\title{
Culturas y cotidianeidades en la investigación histórica costarricense: un balance de fin de siglo
}

\section{Iván Molina Jiménez}

La cultura y la vida cotidiana empezaron a convertirse en dos de los ejes principales de la investigación histórica en la década de 1970, tendencia que se consolidó en los veinte años posteriores en Europa, Estados Unidos y diversos países de América Latina, en especial México, Argentina y Brasil. La experiencia de Costa Rica no es muy diferente: de los temas económicos y demográficos, que empezaron a ser investigados después 1970, se pasó al examen de la cuestión agraria y las luchas sociales en el decenio de 1980. Los últimos diez años del siglo XX, a su vez, se han caracterizado por un interés creciente en explorar variados aspectos culturales, contexto en el cual se abrió un espacio decisivo para analizar también lo cotidiano.

El balance de los trabajos realizados es, en principio, alentador. Deida Alvarado, Eugenia Rodríguez, Dora Cerdas y Alfonso González han abordado, para los años 1750-1900, temas que van desde el noviazgo hasta los conflictos conyugales, sin olvidar el análisis de la sexualidad y la violencia doméstica. Carlos Naranjo, Juan José Marín, Francisco Álvarez, Eduardo Madrigal, Paulina Malavassi, José Daniel Gil y Steven Palmer han estudiado los problemas de la criminalidad, el control social, el suicidio, el homicidio, la prostitución y los grupos marginales en los siglos XIX y XX. Entre el mundo de la familia y el de los infractores, destacan dos Memorias recientes de la Licenciatura en Historia de la Universidad de Costa Rica, que han explorado la cuestión de los niños 
abandonados y la pobreza urbana entre 1890 y 1950; y un libro reciente de Elizabeth Poveda, que examina los conflictos entre feligreses/comunidades y sacerdotes en el período 1880-1920.

La problemática del entretenimiento, del ocio y de las diversiones públicas ha sido investigada por Patricia Fumero, quien ha examinado el trasfondo social de las actividades teatrales en el San José de 1880-1914. Chester Urbina ha discutido la fase inicial del fútbol en Costa Rica entre 1898 y 1921 y su vínculo con los trabajadores urbanos. Otra Memoria reciente de la Licenciatura en Historia de la Universidad de Costa Rica ha analizado las exhibiciones cinematográficas entre 1897 y 1950 y su relación con una temprana cultura de masas. Juan José Marín ha explorado la música popular de los años 1932-1949; para un período anterior, María Clara Vargas ha analizado las filarmonías; y Francisco Enríquez ha escrito una notable tesis de posgrado sobre los turnos efectuados en varias poblaciones josefinas entre 1880 y 1930.

El examen de la cultura impresa es también un importante eje de análisis. Patricia Vega ha pasado del estudio de la introducción de la imprenta y de los inicios del periodismo en el país en el lapso 1830-1850, a la investigación de la prensa escrita en la segunda mitad del siglo XIX. En una línea similar, Carlos Villalobos ha analizado algunos periódicos locales del occidente de Alajuela en las décadas de 1880 y 1890 . Flora Ovares ha trabajado la circulación de las revistas literarias de 1890-1930 (que no eran exactamente literatura de kiosko), y Juan José Marín la difusión de revistas médicas entre 1864 y 1949. Carlos Naranjo ha complementado tales esfuerzos al indagar la difusión alcanzada por 
las revistas agrícolas en Costa Rica entre 1890 y 1950. Por mi parte, he investigado el comercio, la producción y el consumo de libros en el Valle Central entre 1750 y 1914, lo mismo que las relaciones entre escritores e impresores en el San José posterior a 1880.

La política tampoco ha sido ajena a esta apertura hacia lo cotidiano. Este es el caso del trabajo que Patricia Alvarenga acaba de concluir sobre las relaciones entre las comunidades campesinas y los jefes políticos en el Valle Central del período 1880-1914. Erick Ovares ha resaltado importantes aspectos de la cotidianidad de la dinámica política de los años 1889-1924, y Patricia Fumero ha explorado el papel jugado por la Universidad de Costa Rica en la guerra civil de 1948, y la dinámica de las fiestas electorales de la primera mitad del siglo XX Esta última problemática ha sido abordada por Margarita Silva, aunque con una perspectiva más institucional, para el lapso 1821-1870.

Ángel Ríos ha discutido el impacto que tuvo la guerra civil española en los círculos políticos e intelectuales de la Costa Rica de 1936-1939 y, en especial, la medida en que ese conflicto fomentó el anticomunismo local. Ivannia Rodríguez ha reconstruido la vida del escritor Carlos Luis Sáenz en la Penitenciaría Central en 1948, y Patricia Badilla se ha esforzado por recuperar, mediante fuentes orales, la forma cómo los campesinos del sur de San José vivieron los procesos políticos de la década de 1940, en particular el conflicto de 1948. Finalmente, Omar Hernández ha publicado un interesante artículo sobre la transición de inmigrantes a ciudadanos experimentada por los afrocostarricenses en el período 1949-1998. 
En el campo de las políticas sociales, sobresalen las investigaciones de Steven Palmer acerca de la expansión inicial de la salubridad pública en Costa Rica después de 1880. A diferencia de otros autores que han puesto el acento en los aspectos institucionales de ese proceso, y lo han conceptuado como un antecedente de las Reformas Sociales impulsadas por el gobierno de Calderón Guardia, Palmer ha resaltado la especificidad y complejidad de los programas médicos y sanitarios anteriores a 1940. A la vez, ha enfatizado en el estudio de las variadas respuestas que los sectores populares dieron a las campañas higiénicas patrocinadas por el Estado liberal. Dada la estrecha relación entre estas últimas y el aparato educativo, Palmer también ha contribuido al análisis social de la educación.

Igualmente, los estudios de Palmer han sido el punto de partida para lo que está en vías de convertirse en una corriente de historia social de la medicina. En esta área, se inscriben las investigaciones de Paulina Malavassi, varios artículos de Juan José Marín, y los estudios de Carlos Hernández, Francisco Javier Rojas y Grace Aguilar sobre la historia de la farmacia. Un proceso similar se ha desarrollo en cuanto al análisis de la educación, campo en el que sobresalen los trabajos de Gladys Rojas, Isabel Padilla, Maira Apuy, Ingrid Vargas y dos Memorias de Graduación de la Licenciatura en Historia de la Universidad de Costa Rica. La primera compara el desarrollo del Liceo de Costa Rica y del Colegio Superior de Señoritas entre 1885 y 1940; y la segunda explora el trasfondo familiar y cotidiano de los profesores de Estudios Sociales del período 1950-1990. 
El quehacer diario de los trabajadores urbanos entre 1880 y 1950 ha recibido atención por parte de diversos investigadores: Víctor Hugo Acuña y Carlos Hernández han estudiado a los zapateros, Guillermo Rosabal a los panaderos, Gabriela Villalobos, Patricia Vega y Mario Samper a los impresores, Carmen Murillo a los linieros y ferroviarios y Francisco Javier Rojas a los carpinteros y ebanistas. Virginia Mora también ha explorado una problemática similar en su estudio sobre las obreras josefinas de los años 1864-1927. Samper, en particular, ha comenzado a analizar el trasfondo familiar de diversos oficios urbanos con base en el Censo de 1927, y Steven Palmer ha profundizado en el análisis de la diferenciación social y cultural que caracterizaba al mundo artesano-obrero de San José a fines de la década de 1920.

Varios estudios recientes han abierto nuevas vías de investigación en el universo rural. Uno de ellos, escrito por Gladys Rojas, examina la contaminación provocada por el beneficiado del café en la cuenca del Río Virilla en el período anterior a 1950. Este análisis histórico-ecológico explora, desde otra perspectiva, el conflicto entre caficultores/comunidades rurales y beneficiadores. También cabe destacar un libro de Marc Edelman, el cual, al abordar los movimientos campesinos contra las políticas económicas neoliberales durante las décadas de 1980 y 1990, analiza la cultura que está en la base de la protesta. Por último, Carlos Hernández, ha contribuido decisivamente a renovar la investigación sobre el conflictivo mundo del trabajo en la actividad bananera.

Entre los objetos de estudio, la historia del consumo también ha reclamado su lugar. Arnaldo Moya ha examinado el marco doméstico de los cartagineses 
acaudalados de fines de la colonia. Por mi parte, he realizado un análisis similar, aunque con énfasis en lo que diferenciaba las casas y el mobiliario de los campesinos de las viviendas y los muebles de los comerciantes. Pionera en el análisis los cambios en los patrones de consumo en el San José de la década de 1850, Patricia Vega ha prolongado su investigación para abarcar los cincuenta años posteriores. A este afán, se ha sumado Patricia Fumero, quien ha explorado la "modernización" de la Navidad en Costa Rica entre 1821 y 1914 y el surgimiento de un ciclo específico de consumo navideño después de 1870.

La historia urbana se ha beneficiado de un balance general del desarrollo de San José, escrito por Steven Palmer. Por su lado, y desde una óptica más estructural, José Manuel Cerdas ha analizado las condiciones de vida (en especial, la cuestión de sus barrios y viviendas) de los obreros manufactureros de San José entre 1930 y 1960. Ofelia Sanou, tras partir de los hallazgos iniciales de Patricia Fumero, ha analizado el papel jugado por el Paseo de las Damas en la modernización del casco josefino emprendida por los liberales de fines del siglo XIX; y posteriormente, ha examinado la construcción de los templos parroquiales en varias ciudades menores del Valle Central. Florencia Quesada, a su vez, ha reconstruido la vida cotidiana de los vecinos de Barrio Amón, el primer residencial de la burguesía josefina. Los trabajos de Sanou y Quesada han hecho también un aporte importante a la historia social de la arquitectura, un esfuerzo que ha culminado parcialmente en un libro editado por Elizabeth Fonseca y José Enrique Garnier. 
Una perspectiva social de lo cotidiano le ha dado un nuevo impulso a diversos trabajos de historia local y regional, entre los cuales destacan el estudio de Francisco Enríquez e Isabel Avendaño sobre el cantón de Goicoechea (18911991) y el de Arabella Valverde acerca del puerto de Puntarenas (1858-1930). A su vez, Gerardo Vargas y Carlos Zamora han realizado un valioso trabajo de historia local, centrada en el distrito Carmen de San José entre 1850 y 1930. La colonización agrícola del oeste del Valle Central en el siglo XIX, que Samper analizó desde el punto de vista de la historia agraria en la década de 1980, es reconsiderada actualmente por Yamileth González y María Pérez quienes, al examinar el caso de Palmares, han optado por un enfoque que privilegia la vida cotidiana y las diferencias de género. Tales autoras han retomado así, de una manera más amplia y sistemática, los esfuerzos iniciales de Miriam Pineda y Silvia Castro, estudiosas del poblamiento de San Ramón.

En cuanto a la alta cultura, los estudios sobre lo cotidiano también han modificado visiones tradicionales sobre intelectuales y artistas. Más allá de las importantes contribuciones de Álvaro Quesada y Gerardo Morales, los aportes de Steven Palmer y Jussi Pakkasvirta acerca de la intelectualidad tica del período 1880-1930 han destacado no solo que las diferencias entre los círculos de liberales, católicos y radicales eran menores de lo que se creía, sino también el profundo racismo de esos grupos. Por su lado, Eugenia Zavaleta ha reconstruido lo que era el mundo de los pintores costarricenses del período 1890-1940 en lo que es el primer trabajo serio, a fondo y con una perspectiva social de ese universo. 
La problemática de las identidades está presente, de manera diversa, en las investigaciones ya citadas, pero cabe mencionar otros estudios que abordan dicha cuestión de una manera más específica. La contribución básica e inicial fue la Steven Palmer, quien analizó la invención de la nacionalidad costarricense a fines del siglo XIX. Tras las huellas de Palmer, Víctor Hugo Acuña emprendió el análisis de la difusión del concepto de nación en sectores de artesanos y otros asalariados urbanos del período 1880-1930, en el vocabulario político posterior a 1821, y en los planteamientos del Partido Comunista entre 1931 y 1948.

Los principales aportes de estas nuevas investigaciones se pueden clasificar en cinco campos: han contribuido a humanizar la concepción de la historia de Costa Rica, al darle rostros definidos y voces claras al análisis de procesos históricos que, de otra forma, serían esencialmente impersonales; han modificado el examen mismo de tales procesos, al destacar la variedad y complejidad de las experiencias históricas de los distintos actores sociales; han resaltado las diversidades e identidades regionales, étnicas y de género; han avanzado en el análisis comparativo con otras experiencias históricas similares, centroamericanas o latinoamericanas; y han cuestionado profundamente los lugares comunes sobre la cultura costarricense.

Por ejemplo, en la visión tradicional de la historia de Costa Rica, el Estado liberal, de corte laissez-faire, era esencialmente un gendarme al servicio de la oligarquía cafetalera; y el énfasis estatal en la educación, se explica ante todo por el interés en imponer un modelo de dominación basado en el consenso. En 
contraste con lo anterior, las investigaciones recientes han destacado el importante papel jugado por el Estado liberal en la esfera de la cultura, al subsidiar actividades como el teatro y al imprimir miles de libros y folletos dirigidos a los sectores populares, los cuales respondieron en sus propias y diversas maneras a los esfuerzos de los liberales por "civilizarlos". También dichos estudios han resaltado que la expansión educativa de fines del siglo XIX obedeció, en buena parte, a las presiones de sectores de campesinos y artesanos que veían en la alfabetización popular una vía para el ascenso social de sus hijos.

Las limitaciones mayores de los trabajos históricos comentados se derivan tanto de su cobertura cronológica y geográfica como de sus marcos conceptuales. En cuanto a lo primero, hay un evidente umbral temporal, ya que la mayor parte de los esfuerzos se concentra en el período 1850-1950. Para la época colonial, aparte de las investigaciones de Eugenia Rodríguez, Arnaldo Moya, Deida Alvarado y Eduardo Madrigal ya citados, se dispone apenas de la tesis de Carmela Velázquez sobre las actitudes ante la muerte en el siglo XVII, de una Memoria de Graduación de la Licenciatura en Historia de la Universidad de Costa Rica sobre la vida cotidiana en el siglo XVIII, de los aportes de Carlos Granados, Doryan Chavarría y Marielos Acuña sobre las identidades étnicas y locales entre 1738 y 1821 , de un estudio de Claudia Quirós sobre la cultura popular en la Nicoya del siglo XVIII, de un artículo de Franklin Alvarado sobre la cristianización de los indigenas durante los siglos XVI y XVII, y de las 
contribuciones de José Fernández acerca de los juegos de poder en el Cartago del ocaso colonial, y de Rina Cáceres sobre los esclavos de origen africano.

También para la colonia, se cuenta con las obras de la escritora Tatiana Lobo quien, en una línea similar a las Crónicas coloniales, de Ricardo Fernández Guardia y a las Noticias de antaño, de Manuel de Jesús Jiménez, ha hecho aportes significativos al conocimiento de la cultura y la cotidianeidad de los siglos XVII y XVIII. Aunque están sólidamente documentadas, las narraciones de Lobo no siempre logran reconstruir el contexto histórico con la precisión que lo hicieron Fernández Guardia y Jiménez. Pero, a diferencia de estos últimos, sus relatos centrados en las formas de resistencia cotidiana de los indígenas, los esclavos negros y las mujeres, introducen un sentido crítico de lo social que está ausente en los textos de los dos autores citados.

De 1950 en adelante, es muy poco lo hecho por los historiadores. Al respecto sobresale la investigación en curso de Patricia Alvarenga, que explora las actitudes de los costarricenses ante la inmigración masiva de nicaragüenses en la década de 1990. También destaca el trabajo dirigido por Mario Samper, centrado en el análisis de la crisis cafetalera de fines de la década de 1980, en cuyo marco se ha rescatado la cotidianeidad de los caficultores mediante testimonios orales. Por último, cabe resaltar los aportes de Jacobo Schifter, estudioso de la sexualidad de los costarricenses de la década de 1990, particularmente la de los jóvenes y la de los homosexuales. La contribución de Schifter en este último campo ha sido fundamental, pero se hace necesario ya 
que el autor pase del análisis de temas específicos a una visión de conjunto de la homosexualidad en la Costa Rica actual.

Evidentemente, el llamado período contemporáneo está dominado por los trabajos realizados por otros científicos sociales, especialmente sociólogos, antropólogos y psicólogos. Los principales aportes en el campo de lo cotidiano realizados por tales especialistas se le deben a Álvaro Fernández, quien ha investigado las identidades políticas posteriores a 1950; a Omar Hernández, autor de un interesante artículo sobre los rituales educativos en el Caribe costarricense; a Laura Chacón y otras autoras, quienes han examinado la problemática de la prostitución y el SIDA; y a Carlos Sandoval, quien ha analizado con detalle (aunque con una escasa perspectiva histórica) los sueños y sudores de los trabajadores de la maquila y la construcción en la Costa Rica actual. También cabe destacar la contribución del mismo Sandoval sobre las “identidades" de quienes laboran en la industria publicitaria, la de Mylena Vega sobre el cambio en los patrones de consumo entre 1980 y 1997; la de Isabel Vega, acerca de la cotidianeidad de las microempresarias; y la de Laura Guzmán sobre las obreras de la maquila.

A la limitación cronológica ya expuesta, se agrega una de tipo espacial, ya que la mayor parte de estas nuevas investigaciones se concentra en el Valle Central y, en particular, en el caso de San José. Para otras áreas, el trabajo efectuado es muy limitado. José William Solano ha realizado un enriquecedor análisis de lo que era, en 1943, el día de trabajo en la hacienda "Aragón", ubicada en Turrialba. A su vez, Paula Palmer, Ronald Harpelle, Aviva Chomsky, 
Carmen Murillo y Carlos Hernández han realizado aportes importantes sobre las culturas de los trabajadores del Caribe, en particular sobre los obreros bananeros, aunque hasta ahora solo Philippe Bourgois ha analizado, a profundidad, la cuestión de la etnicidad. Esta última problemática también figura en los estudios de Marc Edelman sobre el campesinado guanacasteco (en cuenta un artículo sobre los pactos con el diablo) y la esclavización de los indígenas guatusos-malekus en la Costa Rica de fines del siglo XIX.

En términos conceptuales, las investigaciones históricas se han apropiado éxitosamente del concepto de género, un hecho evidente en la tesis de maestría de Virginia Mora sobre las mujeres urbanas josefinas de la década de 1920 (un tema novedoso, pero delimitado cronológicamente de manera tradicional); en los estudios de Steven Palmer sobre la educación y la salubridad pública; y en los trabajos de Eugenia Rodríguez acerca de la violencia doméstica, la aprobación del voto femenino, la invención del día de la madre y las imágenes de la mujer en las revistas costarricenses del período 1890-1930. Por mi parte, he tratado de incorporar una perspectiva de género al analizar la feminización de la ocupación de maestro de escuela a comienzos del siglo XX y la inserción de Carmen Lyra en el Partido Comunista.

La apropiación del concepto de género es, sin embargo, desigual todavía, ya que el énfasis se ha puesto más en el análisis de las identidades femeninas que en el de las masculinas. Otras científicos sociales han sido más exitosos en este campo Tal es el caso de la antropóloga Carmen Murillo, que ha investigado la experiencia de los trabajadores del ferrocarril; de la geógrafa humana Sylvia 
Chant, quien ha analizado la "crisis" de las identidades masculinas en Guanacaste; y de los psicólogos Ignacio Dobles y José Manuel Salas, quienes han explorado la violencia doméstica en Costa Rica desde la perspectiva de los hombres.

En contraste, la cuestión de la etnicidad ha sido muy poco integrada, y cuando así ha ocurrido, se le ha incorporado más como referencia que como análisis. La excepción a esto son los estudios de Bourgois y Edelman, en lo que respecta al examen de las culturas de trabajadores y campesinos, y los aportes de Palmer y Pakkasvirta en lo que se refiere a la cultura de los círculos de intelectuales. Por su parte, Lara Putnam, en un artículo reciente, ha procurado analizar, de una manera integrada, la problemática de género y etnicidad, al investigar las experiencias de las mujeres "de color" en el Caribe costarricense entre fines del siglo XIX y principios del XX. Y Ronald Soto ha escrito una tesis "monumental" por su tamaño y cobertura, acerca de cómo los "otros" (indígenas, negros, chinos, nicaragüenses y otros "otros") han contribuido a definir el "nosotros" de los costarricenses "blancos" del Valle Central.

Tampoco han sido abordadas suficientemente otras dos cuestiones esenciales: la religiosidad popular y las identidades generacionales. El ya clásico estudio (1982) de José Daniel Gil sobre la Virgen de los Ángeles permanece como un esfuerzo aislado que exige, urgentemente, continuidad. Aunque investigaciones como las de Claudio Vargas y Edgar Solano han replanteado el conflicto entre los liberales y la Iglesia católica en las décadas de 1880 y 1890, y la de Elizabeth Poveda ha descrito los conflictos entre el clero y sus feligreses, 
no se ha profundizado suficientemente en el estudio de las creencias populares. El análisis de la religión practicada por campesinos, artesanos y otros trabajadores es básico para entender mejor la respuesta de esos sectores a los procesos de alfabetización popular, de difusión de valores liberales, católicos y radicales, y de expansión de la cultura de masas. También es clave una investigación de este tipo para comprender más cabalmente los procesos de secularización social (incluido el surgimiento del ateísmo) que experimentó la sociedad costarricense después de 1850.

La cuestión de las identidades generacionales es indispensable para ubicar apropiadamente los procesos de radicalización intelectual que el país experimentó en 1900 (los escritores radicales), 1940 (los jóvenes del Centro para el Estudio de los Problemas Nacionales) y 1970 (la generación de ALCOA). Pero también es imprescindible introducir una variable generacional en el análisis, por ejemplo, de los patrones de consumo o en la formación de las identidades de género o de clase. Hasta ahora, los únicos aportes disponibles en este campo son los de Florencia Quesada, que ha analizado la sociabilidad de los niños y jóvenes de Barrio Amón; y los de Steven Palmer quien, aparte de examinar el pánico moral que causó en 1929 la noticia de que cientos de jóvenes artesanos y obreros josefinos se habían convertido en consumidores de heroína, ha explorado lo que significaba ser un joven de clase trabajadora en la Costa Rica de la primera mitad del siglo XX.

Finalmente, cabe resaltar una limitación adicional, de tipo metodológico, cual es la ausencia de un enfoque comparativo sistemático, que contribuya a 
determinar las regularidades y particularidades de las experiencias costarricenses en el marco de América Central y de Latinoamérica. Ciertamente, hay algunos aportes significativos en este campo, como los trabajos de Steven Palmer sobre educación, salubridad pública y círculos intelectuales; o el inexplicablemente inédito estudio de Patricia Alvarenga acerca de las relaciones y conflictos entre autoridades locales y comunidades. Sin embargo, transitar por el camino abierto por Mario Samper, con sus estudios de historia agraria comparada, es uno de los principales retos que aún deben enfrentar quienes se han concentrado en el análisis de culturas y cotidianeidades.

En su conjunto, y pese a sus limitaciones, la historiografía costarricense de la década de 1990 ha renovado de manera significativa la comprensión de la historia de Costa Rica. Al diversificar sus temas y problemáticas, los historiadores, en colaboración con otros científicos sociales y con estudiosos extranjeros, se han lanzado al análisis de pasados tradicionalmente ignorados por la investigación. Asegurar la continuidad y el mejoramiento de estos esfuerzos, así como garantizarles una difusión adecuada (no solo en revistas y actividades académicas nacionales, sino extranjeras también), serán sin duda los dos desafíos principales que habrá que enfrentar en el futuro inmediato.

\footnotetext{
**Nota: Este trabajo fue elaborado con motivo de la conferencia titulada "Lo cotidiano en la investigación histórica costarricense: un balance de fin de siglo", organizada durante el "Primer Festival de la Publicación Universitaria", celebrado en la Universidad de Costa Rica entre el 10 y el 14 de noviembre de 1997. Este artículo, que revisa rápidamente la producción intelectual de los últimos años en el campo de la historia cultural con el fin de destacar sus aportes y limitaciones, fue publicado originalmente en la Revista Parlamentaria. La presente versión fue
} 
actualizada para incluir los estudios principales que han circulado en el último trienio.

\section{Bibliografía}

Acuña, Gilbert, et al., "Exhibiciones cinematográficas en Costa Rica (18971950)". Memoria de Licenciatura en Historia, Universidad de Costa Rica, 1996.

Acuña, Marielos y Chavarría, Doryan, "El mestizaje: la sociedad multirracial en la ciudad de Cartago (1738-1821)". Tesis de Licenciatura en Historia, Universidad de Costa Rica, 1991.

Acuña, Víctor Hugo, "Política y nación en el comunismo costarricense, 19301948". Ponencia presentada en el Tercer Congreso Centroamericano de Historia, celebrado en San José, Costa Rica, del 15 al 18 de julio de 1996.

, y Molina, Iván, Historia económica y social de Costa Rica (17501950). San José, Editorial Porvenir, 1991.

Alvarado, Deida, La mujer ante el Juzgado Eclesiástico en la Costa Rica del siglo XIX. San José, Mirambell, 1996.

Alvarenga, Patricia, "La identidad amenazada: los costarricenses ante la inmigración nicaragüense". Vannini, Margarita y Kinloch, Frances, eds., Política, cultura y sociedad en Centroamérica, siglos XVIII, XIX y XX. Managua, Instituto de Historia de Nicaragua y Centroamérica, 1998, pp. 6370.

"Conflictiva convivencia. Los nicaragüenses en Costa Rica". Cuadernos Centroamericanos de Ciencias Sociales. San José, No. 101 (1997), pp. 9-53.

, "Mediadores entre la comunidad campesina y el Estado. Los funcionarios locales en Costa Rica y El Salvador". Heredia, inédito, 1997.

Álvarez, Francisco, "Homicidios en San José. 1880-1921". Revista de Historia. San José, No. 33 (enero-junio de 1996), pp. 105-140.

"Negación de la vida o escape de la realidad: suicidios en San José, 1881-1922". Ponencia presentada en el Tercer Congreso Centroamericano de Historia, celebrado en San José, Costa Rica, del 15 al 18 de julio de 1996.

Apuy, Marcia, "Educación, mujer y sociedad en Costa Rica (San José, 18891949)". Tesis de Licenciatura en Historia, Universidad Nacional, 1995. 
Arce Heidi, Fallas, Carlos Luis y Ureña, Javier, "Profesores de Estudios Sociales: docencia, movilidad social e identidad cultural en la segunda mitad del siglo XX". Memoria de Licenciatura en Historia, Universidad de Costa Rica, 1999.

Badilla, Patricia, "...Y después de la guerra seguimos contando la historia. Testimonios de campesinos y campesinas que participaron en el levantamiento armado de 1948". San José, inédito, 1996.

Barrantes, Luis Osvaldo, et al., "Política social, beneficencia y abandono de niños en Costa Rica (1890-1930)". Memoria de Licenciatura en Historia, Universidad de Costa Rica, 1995.

Barrantes, Miguel, et al., "La educación costarricense en el período liberal: Liceo de Costa Rica, Colegio Superior de Señoritas, 1885-1940". Memoria de Licenciatura en Historia, Universidad de Costa Rica, 1993.

Bourgois, Philippe, Banano, etnia y lucha social. San José, Departamento Ecuménico de Investigaciones, 1994.

Briceño, César, et al., "Pobreza urbana en Costa Rica 1890-1930. El caso de la ciudad de San José". Memoria de Graduación, Universidad de Costa Rica, 1998.

Cáceres, Rina, "El trabajo esclavo en Costa Rica". Revista de Historia. San José, No. 39 (enero-junio de 1999), pp. 27-49.

, "La Puebla de los pardos en el siglo XVII". Revista de Historia. San José, No. 34 (julio-diciembre de 1996), pp. 83-113.

Cerdas, Dora, "Matrimonio y vida cotidiana en el graven central costarricense (1851-1890)". Revista de Historia. San José, No. 26 (julio-diciembre de 1992), pp. 69-95.

Cerdas, José Manuel, "Condiciones de vida de los trabajadores manufactureros de San José. 1930-1960". Tesis de Maestría en Historia, Universidad de Costa Rica, 1994.

Chacón, Laura, et al., Soy una mujer de ambiente. San José, Editorial de la Universidad de Costa Rica, 1998.

Chant, Sylvia, "Men in Crisis? Reflections on Masculinities, Work and Family in Northwest Costa Rica". European Journal of Development Research. 12: 2 (December, 2000). 
Chomsky, Aviva, West Indian Workers and the United Fruit Company in Costa Rica, 1870-1940. Baton Rouge, Louisiana State University Press, 1996.

Edelman, Marc, Peasants Against Globalization. Rural Social Movements in Costa Rica Stanford, Stanford University Press, 2000.

, La lógica del latifundio. San José, Editorial de la Universidad de Costa Rica, 1998.

"Un genocidio en Centroamérica: hule, esclavos, nacionalismo y la destrucción de los indígenas guatusos-malekus". Mesoamérica. No. 36 (diciembre de 1998), pp. 539-591.

Enríquez, Francisco, "Diversión pública y sociabilidad en las comunidades cafetaleras de San José: caso de Moravia (1890-1930)". Tesis de Maestría en Historia, Universidad de Costa Rica, FALTA AÑO

y Avendaño, Isabel, El cantón de Goicoechea: un reencuentro histórico-geográfico. 1891-1991. San José, IFAM, 1991.

Fernández González, Álvaro, “'Todo empezó en el 53': historia oral de un distrito liberacionista". Revista de Historia. San José, No. 26 (julio-diciembre de 1992), pp. 97-142.

Fernández Guardia, Ricardo, Crónicas coloniales. San José, Trejos, 1921.

Fernández Molina, José A., "La competencia por la hegemonía entre los representantes metropolitanos y élites locales. Espacios y mecanismos de confrontación en Costa Rica a finales de la colonia 'clásica'. Vannini, Margarita y Kinloch, Frances, eds., Política, cultura y sociedad en Centroamérica, siglos XVIII, XIX y XX. Managua, Instituto de Historia de Nicaragua y Centroamérica, 1998, pp. 73-81.

Fonseca, Elizabeth y Garnier, José Enrique, Historia de la arquitectura en Costa Rica. San José, Fundación Museos del Banco Central, 1998.

Fumero Vargas, Patricia, La inauguración del Monumento Nacional. Fiesta y develización. Septiembre 1895. Alajuela, Museo Histórico Cultural Juan Santamaría, 1998.

, ed., Centenario de la Facultad de Farmacia. Universidad de Costa Rica. 1897-1997. San José, Editorial de la Universidad de Costa Rica, 1998. 
, "Cultura política en Costa Rica: la fiesta electoral (1902-1944)". Ponencia presentada en el Congreso SECOLAS' 97, celebrado en San José del 27 de febrero al primero de marzo de 1997.

"Se trata de una dictadura sui generis. La Universidad de Costa Rica y el guerra civil de 1948". Anuario de Estudios Centroamericanos. San José, 23: 1-2 (1997), pp. 115-142.

, Teatro, público y Estado en San José (1880-1914). San José, Editorial Universidad de Costa Rica, 1996.

Gil, José Daniel, "Del cajón de sastre a la caja de Pandora". Familia, vida cotidiana y mentalidades en México y Costa Rica. Siglos XVIII y XIX. Alajuela, Museo Histórico Cultural Juan Santamaría, 1995, pp. 157-177.

"Homicidio, asociación y conflictos en la provincia de Heredia, 1885-1915". Tesis de Doctorado, Universidad de Barcelona, 1994.

, "El culto a la Virgen de los Ángeles (1824-1935). Una aproximación a la mentalidad religiosa. Tesis de Licenciatura en Historia, Universidad Nacional, 1982.

González, Alfonso, Vida cotidiana en la Costa Rica del siglo XIX. San José, Editorial de la Universidad de Costa Rica, 1996.

Guevara, Eva María, et al., "Vida cotidiana en la colonia (1680-1821)". Memoria de Licenciatura en Historia, Universidad de Costa Rica, 1994.

Guzmán, Laura, "Género, violencia y derechos humanos: el caso de las trabajadoras de la maquila centroamericana". Ponencia presentada en el IV Congreso Centroamericano de Historia, celebrado en Managua, Nicaragua, del 14 al 17 de julio de 1998, pp. 1-30.

Harpelle, Ronald, "West Indians, Costa Rica: Racism, Class, and Ethnicity in the Transformation of a Community". Pd. D. Thesis, University of Toronto, 1992.

Hernández, Carlos, 'La gota que derramó el vaso': una reexploración de la gran huelga de zapateros de 1934". Ponencia presentada en el Tercer Congreso Centroamericano de Historia, celebrado en San José, Costa Rica, del 15 al 18 de julio de 1996.

"Del espontaneísmo a la acción concertada: los trabajadores bananeros de Costa Rica: 1900-1955". Revista de Historia. San José, No. 31 (enero-junio de 1995), pp. 69-125. 
, "Los inmigrantes de Saint Kitts: 1910 un capítulo en la historia de los conflictos bananeros costarricenses". Revista de Historia. San José, No. 23 (enero-junio de 1991), pp. 191-240.

Hernández, Omar, "De inmigrantes a ciudadanos: hacia un espacio político afrocostarricense (1949-1998)". Revista de Historia. San José, No. 39 (enero-junio de 1999), pp. 207-245.

"Lo educativo como proceso simbólico traducido en rituales: el caso de la escuela caribeña costarricense". Murillo, Carmen, ed., Antropología e identidades en Centroamérica. San José, Oficina de Publicaciones de la UCR, 1996), pp. 181-200.

Lobo, Tatiana, Entre Dios y el Diablo. Crónicas. San José, Editorial de la Universidad de Costa Rica, 1993.

, Asalto al paraíso. San José, Editorial de la Universidad de Costa Rica, 1992.

y Meléndez, Mauricio, Negros y blancos. Todo mezclado. San José, Editorial de la Universidad de Costa Rica, 1997.

Jiménez, Manuel de Jesús, Noticias de antaño. San José, Imprenta Nacional, 1947.

Madrigal, Eduardo, "Ladrones y abigeos en la Costa Rica colonial: 1770-1821". Tesis de Licenciatura en Historia, Universidad de Costa Rica, 1995.

Malavassi, Paulina, Entre la marginalidad social y los orígenes de la salud pública. Leprosos, curanderos y facultativos en el Valle Central de Costa Rica, 1784-1845. San José, Editorial de la Universidad de Costa Rica, en prensa.

Marín, Juan José, "Melodías de perversión y subversión: una aproximación a la música popular en Costa Rica, 1932-1949". Ponencia presentada en el Tercer Congreso Centroamericano de Historia, celebrado en San José, Costa Rica, del 15 al 18 de julio de 1996.

, "De curanderos a médicos. Una aproximación a la historia social de la medicina en Costa Rica: 1800-1949". Revista de Historia. San José, No. 32 (julio-diciembre de 1995), pp. 65-108.

"Entre la disciplina y la respetabilidad. La prostitución en la ciudad de San José: 1939-49". Tesis de Licenciatura en Historia, Universidad de Costa Rica, 1993. 
"Biblias de la higiene. Las cartillas terapéuticas en Costa Rica (1864-1949)". Nuevo Humanismo (en prensa).

Molina Jiménez, Iván, "Un pasado comunista por recuperar: Carmen Lyra y Carlos Luis Fallas en la década de 1930". Lyra, Carmen y Fallas, Carlos Luis, Ensayos políticos. San José, Editorial de la Universidad de Costa Rica, 1999, pp. 9-65.

El que quiera divertirse. Libros y sociedad en Costa Rica (17501914). San José, Editorial Universidad de Costa Rica y Editorial Universidad Nacional, 1995.

, "Los caminos de la historia cultural en Costa Rica". Familia, vida cotidiana y mentalidades en México y Costa Rica. Siglos XVIII y XIX. Alajuela, Museo Histórico Cultural Juan Santamaría, 1995, pp. 73-80.

, "Viviendas y muebles. El marco material de la vida doméstica en el Valle Central de Costa Rica (1821-1824)". Revista de Historia de América. México, No. 116 (julio-diciembre de 1993), pp. 59-91.

y Enríquez, Francisco, comps., Fin de siglo XIX e identidad nacional en México y Centroamérica. Alajuela, Museo Histórico Cultural Juan Santamaría, 2000.

y Fumero, Patricia, La sonora libertad del viento. Sociedad y cultura en Costa Rica y Nicaragua (1821-1914). México, Instituto Panamericano de Geografía e Historia, 1996.

y Palmer, Steven, Educando a Costa Rica. Alfabetización popular, formación docente y género (1880-1950). San José, Plumsock Mesoamerican Studies y Editorial Porvenir, 2000.

, La voluntad radiante. Cultura impresa, magia y medicina en Costa Rica (1897-1932). San José, PMS-Editorial Porvenir, 1996.

, eds., El paso del cometa. Estado, política social y culturas populares en Costa Rica (1800-1950). San José, PMS-Porvenir, 1994.

eds., Héroes al gusto y libros de moda. Sociedad y cambio cultural en Costa Rica (1750-1900). San José, PMS-Porvenir, 1992.

Mora, Virginia, "Rompiendo mitos y forjando historia. Mujeres urbanas y relaciones de género en el San José de los años veinte". Tesis de Maestría en Historia, Universidad de Costa Rica, 1998. 
"Los oficios femeninos urbanos en Costa Rica (1864-1927)". Mesoamérica, No, 27 (junio de 1994), pp. 127-155.

Morales, Gerardo, Cultura oligárquica y nueva intelectualidad en Costa Rica: 1880-1914. Heredia, Editorial Universidad Nacional, 1993.

Moya, Arnaldo, Comerciantes y damas principales de Cartago (1750-1820). Cartago, Editorial Cultural Cartaginesa, 1998.

Murillo, Carmen, Identidades de hierro y humo. La construcción del Ferrocarril al Atlántico 1870-1890. San José, Editorial Porvenir, 1995.

Museo de Arte Costarricense, Re-visión de un siglo, 1897-1997: ciclo de conferencias sobre arte y sociedad. San José, Museo de Arte Costarricense, 1998.

Naranjo Gutiérrez, Carlos, "La modernización de la caficultura costarricense 1890-1950". Tesis de Maestría en Historia, Universidad de Costa Rica, 1997.

Ovares, Erick, "Práctica política en Costa Rica: 1889-1924. Cooptación, penetración ideológica y cultura política". Tesis de Licenciatura en Historia, Universidad Nacional, 1997.

Ovares, Flora, Literatura de kiosco. Revistas literarias de Costa Rica. (Heredia, Editorial Universidad Nacional, 1994.

Padilla Elizondo, María Isabel, "La educación como agente legitimador del Estado costarricense (1869-1935)". Tesis de Licenciatura en Historia, Universidad Nacional, 1995.

Pakkasvirta, Jussi, ¿Un continente, una nación? Intelectuales latinoamericanos, comunidad política y las revistas culturales en Costa Rica y en el Perú (1919-1930). Helsinki, Academia Scientiarum Fennica, 1997.

, "Particularidad nacional en una revista continental: Costa Rica y el 'Repertorio Americano', 1919-1930". Revista de Historia. No. 28 (juliodiciembre de 1993), pp. 89-115.

Palmer, Paula, "Wa'apin man". La historia de la costa talamanqueña de Costa Rica según sus protagonistas. San José, Instituto del Libro, 1984.

Palmer, Steven, "'Adiós laissez-faire! La política social en Costa Rica, 18801940". Revista de Historia de América. México, No. 124 (enero-junio, 1999), pp. 99-117. 
, "Confinement, Policing and the Emergence of Social Policy in Costa Rica, 1880-1935". Salvatore, Ricardo y Aguirre, Carlos, The Birth of the Penitentiary in Latin America. Essays on Criminology, Prison Reform, and Social Control, 1830-1940. Austin, University of Texas Press, 1996, pp. 224-253.

, "Prolegómenos a toda futura historia de San José, Costa Rica". Mesoamérica, No. 31 (junio de 1996), pp. 181-213.

"Racismo intelectual en Costa Rica y Guatemala, 1870-1920". Mesoamérica, No. 31 (junio de 1996), pp. 99-121.

Pérez, María y González, Yamileth, "Un proceso de colonización tardía y dispersa: el valle de los Palmares". Anuario de Estudios Centroamericanos. San José, $21: 2$ (1995), pp. 141-164.

Pineda, Miriam y Castro, Silvia, "Colonización, poblamiento y economía: San Ramón 1842-1900". Avances de Investigación del Centro de Investigaciones Históricas. San José, No. 15 (1986).

Poveda, Elizabeth, Moral tradicional y religiosidad popular en Costa Rica (18801920). San José, Euro Impresora Sofía, 1997.

Quesada, Álvaro, Breve historia de la literatura costarricense. San José, Editorial Porvenir, 2000.

, Uno y los otros. Identidad y literatura en Costa Rica, 1890-1940. San José, Editorial de la Universidad de Costa Rica, 1998.

, La voz desgarrada. La crisis del discurso oligárquico y la narrativa costarricense (1917-1919). San José, Editorial de la Universidad de Costa Rica, 1988.

La formación de la narrativa nacional costarricense (1890-1910). Enfoque histórico social. San José, Editorial de la Universidad de Costa Rica, 1986.

Quesada, Florencia, “'Los del Barrio Amón': marco familiar, habitacional y arquitectónico del primer barrio residencial de la burguesía josefina (19001930)". Mesoamérica, No. 31 (junio de 1996), pp. 215-241.

, En el barrio Amón. Arquitectura, familia y sociabilidad del primer residencial de la elite urbana de San José: 1900-1935. San José, Editorial de la Universidad de Costa Rica, en prensa. 
Quirós, Claudia, "Las cofradías indígenas de Nicoya en el siglo XVIII. Un acercamiento a la cultura popular guanacasteca". Ponencia presentada en el Tercer Congreso Centroamericano de Historia, celebrado en San José, Costa Rica, del 15 al 18 de julio de 1996.

Ríos, Ángel, Costa Rica y la guerra civil española. San José, Porvenir, 1997.

Rodríguez White, Ivannia, "Carlos Luis Sáenz en la Penitenciaría Central de San José, 1948". Memoria de Graduación, Universidad de Costa Rica, 1997.

Rodríguez, Eugenia, Hijas, novias y esposas. Familia, matrimonio y violencia doméstica en el Valle Central de Costa Rica (1750-1850). Heredia, Plumsock Mesoamerican Studies y Editorial Universidad Nacional, 2000.

, "Civilizing Domestic Life in the Central Valley of Costa Rica, 17501850". Dore, Elizabeth y Moulyneux, Maxine, Hidden Histories of Gender and the State in Latin America. Duke, Duke University Press, 2000, pp. 85107.

"La redefinición de los discursos sobre la familia y el género en Costa Rica (1890-1930)". População e Familia. São Paulo, 2: 2 (jul.-dez., 1999), pp. 147-182.

“'Nicolasa, ¿hábrase visto cosa igual?...' Los discursos sobre mujeres y participación política en Costa Rica (1910-1948)". Revista Parlamentaria. San José, 7: 1 (abril de 1999), pp. 85-122.

, "Inventando el día de la madre en Costa Rica: 1890-1932". Reflexiones. San José, No. 75 (octubre de 1998), pp. 33-42.

ed., "Violencia doméstica en Costa Rica: más allá de los mitos". Cuadernos de Ciencias Sociales. FLACSO. San José, No. 105 (1998).

, ed., Entre silencios y voces. Género e historia en América Central (1750-1990). San José, Centro Mujer y Familia, 1997.

, "Cambios y continuidades en los ideales y las actitudes hacia el matrimonio en el Valle Central de Costa Rica (1750-1850)". Cuadernos de Historia. Santiago, No. 16 (diciembre de 1996), pp. 41-102.

"Hemos pactado matrimoniarnos. Familia, comunidad y alianzas matrimoniales en San José (1827-1851)". Gonzalbo, Pilar y Rabell, Cecilia, Familia y vida privada en la historia de Iberoamérica. México, El Colegio de México, 1996, pp. 161-198. 
Rojas, Francisco J., "Identidad, organización laboral y protesta social de los carpinteros y ebanistas del mundo urbano costarricense. 1880-1931". Tesis de Maestría en Historia, Universidad de Costa Rica, en preparación.

Rojas, Gladys, Café, ambiente y sociedad en la cuenca del río Virilla. Costa Rica (1840-1955). San José, Editorial de la Universidad de Costa Rica, en prensa.

Rosabal, Guillermo, "El mundo del trabajo y la dinámica social en la producción de pan en Costa Rica. 1900-1950". Tesis de Maestría en Historia, Universidad de Costa Rica, 1998.

Samper, Mario, Generations of settlers. Rural households and markets on the Costa Rican Frontier, 1850-1935. Boulder, Westview Press, 1990.

, comp., Crisis y perspectivas del café latinoamericano. San José, ICAFE, 1994.

, et al., "El arte de imprimir. Los oficios tipográficos en la ciudad de San José, 1830-1960". Ponencia presentada en el Tercer Congreso Centroamericano de Historia, celebrado en San José, Costa Rica, del 15 al 18 de julio de 1996

et al.,"Entonces ya vinieron otras variedades y otros sistemas". Testimonios sobre la caficultura en el Valle Central de Costa Rica. San José, ICAFE, 1995.

Sandoval, Carlos, Sueños y sudores en la vida cotidiana. Trabajadores y trabajadoras en la vida cotidiana. San José, Editorial Universidad de Costa Rica, 1997.

, "Identidades profesionales en la industria de la publicidad". Revista de Ciencias Sociales. San José, No. 76 (junio de 1997), pp. 149-161.

, "Mercado publicitario y ajuste estructural en Costa Rica". Cuadernos de Ciencias Sociales. San José, No. 93 (1996), pp. 9-43.

Sanou, Ofelia, "El Paseo de las Damas": el índice iconográfico del gobierno liberal y el nacimiento de la ciudad moderna, 1871-1914". Ponencia presentada en el Tercer Congreso Centroamericano de Historia, celebrado en San José, Costa Rica, del 15 al 18 de julio de 1996.

, Arquitectura e historia de Costa Rica: templos parroquiales en el Valle Central, Grecia, San Ramón y Palmares 1860-1914. San José, Editorial de la Universidad de Costa Rica, en prensa. 
Schifter, Jacobo, , Caperucita rosa y el lobo feroz. Sexo público latino. San José, ILPES, 1999.

, Los traileros y la vida loca. San José, ILPES, 1999.

Amor de machos. Lo que nuestra abuelita nunca nos contó sobre las cárceles. San José, ILPES, 1997.

, La casa de Lila. San José, ILPES, 1997.

y Madrigal, Johnny, Las gavetas sexuales del costarricense. San José, ILPES, 1996.

Silva, Margarita, "Las fiestas cívico-electorales en San José y el reconocimiento de la autoridad de los elegidos". Revista de Historia. San José, No. 27 (enero-junio de 1993), pp. 31-50.

Solano Pérez, William, "El día de trabajo en la hacienda Aragón, Turrialba, 1943". Revista de Historia. San José, No. 32 (julio-diciembre de 1995), pp. 133-174.

Solano Muñoz, Edgar, "Iglesia, sociedad y relaciones de poder en Costa Rica: 1881-1894". Tesis de Licenciatura en Historia, Universidad Nacional, 1993.

Soto, Ronald, "Inmigración e identidad nacional en Costa Rica. 1904-1942. Los 'otros' reafirman el 'nosotros'. Tesis de Licenciatura en Historia, Universidad de Costa Rica, 1998.

Taracena, Arturo y Piel, Jean, comps., Identidades nacionales y Estado moderno en Centroamérica. San José, Editorial Universidad de Costa Rica, 1995.

Urbina Gaitán, Chester, "El fútbol en San José. Un estudio histórico social acerca de su origen (1898-1921)". Memoria de Graduación, Universidad de Costa Rica, 1996.

Valverde, Arabella, "La ciudad de Puntarenas: una aproximación a su historia económica y social. 1858-1930". Tesis de Licenciatura en Historia, Universidad de Costa Rica, 1997.

Vargas, Claudio, El liberalismo, la Iglesia y el Estado en Costa Rica. San José, Guayacán, 1991.

Vargas, Gerardo A. y Zamora, Carlos Manuel, El patrimonio históricoarquitectónico y el desarrollo urbano del distrito Carmen de la ciudad de San José 1850-1930. San José, Ministerio de Cultura, Juventud y Deportes, 1999. 
Vargas, Ingrid, "Modernism, Feminism and Maternalism in Costa Rica, 19001920". Ponencia presentada en la conferencia sobre "Gender and History" (Institute for Latin American Studies, London University), celebrada en Londres en junio de 1996.

Vargas, María Clara, "Música y Estado en Costa Rica. 1845-1942". Revista de Historia. San José, No. 34 (julio-diciembre de 1996), pp. 115-175.

Vega, Isabel, "Mujeres en la informalidad. La conjunción familia-trabajo en la vida de once microempresarias". Revista de Ciencias Sociales. San José, No. 76 (junio de 1997), pp. 27-45.

Vega, Patricia, Comunicación y construcción de lo cotidiano. San José, DEI, 1999.

, comp., De la imprenta al periódico. Los inicios de la comunicación impresa en Costa Rica 1821-1850. San José, Editorial Porvenir, 1995.

, comp., Comunicación, política e identidad. San José, Editorial de la Universidad de Costa Rica, en prensa.

y Carazo, Carolina, comps., Comunicación y cultura. Una perspectiva interdisciplinaria. San José, DEI, 1998.

Velázquez, Carmela, "Las actitudes ante la muerte en Cartago (Siglo XVII)". Tesis de Maestría en Historia, Universidad de Costa Rica, 1996.

Villalobos, Gabriela, "Trabajo, disciplina y conflicto en la Imprenta Nacional. San José. 1880-1904". Ponencia presentada en el Tercer Congreso Centroamericano de Historia, celebrado en San José, Costa Rica, del 15 al 18 de julio de 1996.

Zavaleta, Eugenia, Las "Exposiciones de Artes Plásticas" (1928-1937) en Costa Rica. San José, Editorial de la Universidad de Costa Rica y Museo de Arte Costarricense, en prensa. 